\title{
What our colleagues says.... Basic anesthetic considerations in neurosurgery
}

Indu, Arvind Chaturvedi

Department of Neuroanaesthesia, Neurosciences Center, All India Institute of Medical Sciences, New Delhi, India

\section{A B S T R A C T}

Rapid development in neurosurgical practice poses new challenges for anaesthesiologists requiring search for newer and safer anaesthetic agents and modification in basic anaesthetic techniques. The present article describes the basic neuroanaesthetic considerations and some of the newer developments in anaesthetic drugs and techniques which are important during neurosurgical practice.

Key words: Anaesthetic agents, anaesthetic techniques, neurosurgery

\section{INTRODUCTION}

Evolution of neurosurgery is accompanied by new challenges for the anesthesiologist. Increasingly, we must think not only as an anesthesiologist but also as a neurosurgeon and neurologist. With the recent advancements and focus on functional and minimally invasive procedures, there is an increased emphasis on the provision of optimal operative conditions, preservation of neurocognitive function, minimizing interference with electrophysiological monitoring, and a rapid, high-quality recovery to facilitate early neurological examination.

Patients who undergo neurosurgery have various types of intracranial pathology and systemic diseases and their responses to anesthetics may be different from those of normal subjects. Brain tissue hypoxia, acidosis, and edema are the main pathologic consequences of most of the brain disorders. Cerebral perfusion pressure (CPP) and carbon dioxide tension in the arterial blood $\left(\mathrm{PaCO}_{2}\right)$ are the important variables that influence cerebral blood flow $(\mathrm{CBF})$. Autoregulation is the physiologic maintenance of constant $\mathrm{CBF}$ over a wide range of CPP values.

\begin{tabular}{|l|l|}
\hline \multicolumn{2}{|c|}{ Access this article online } \\
\hline Quick Response Code: & Website: \\
\hline & www.ijns.in \\
\cline { 2 - 2 } & \\
\hline
\end{tabular}

Anesthetic drugs and techniques influence cerebral circulation, metabolism and ICP. Some anesthetic drugs may have a potential for neuroprotective effects. Major goals in neurosurgical anesthesia are to provide adequate tissue perfusion to the brain so that the regional metabolic demand is met and to provide adequate surgical conditions (a "relaxed brain"). If anesthetic drugs or anesthetic techniques are improperly used, they can worsen the existing intracranial pathology and may produce new damage. Some anesthetics or anesthetic techniques may help to protect the brain subjected to metabolic stress or even ameliorate damage from such an insult.

\section{EFFECTS OF ANESTHETIC DRUGS}

Inhalational Anesthetics

In general intravenous anesthetics decrease cerebral metabolic rate (CMR) and $\mathrm{CBF}$, whereas most inhalational anesthetics decrease CMR with an increase in CBF. All inhalational anesthetics are cerebral vasodilators and possess the capability of increasing ICP. Inhalational anesthetics with the possible exception of nitrous oxide $\left(\mathrm{N}_{2} \mathrm{O}\right)$, usually depress metabolism. Despite the disassociation of $\mathrm{CBF}$ and $\mathrm{CMRO}_{2}$, changes in the magnitude of cerebral vasodilation appear to be related to the level of tissue metabolism.

Nitrous oxide

Nitrous oxide continues to generate debate in neuroanesthesia in terms of its effect on cerebral dynamics (CBF, CMR and ICP). Classic studies in humans demonstrated that $\mathrm{N}_{2} \mathrm{O}$ did not significantly

Address for correspondence: Dr. Arvind Chaturvedi,

Department of Neuroanaesthesia, Neurosciences Center, All India Institute of Medical Sciences, Ansari Nagar, New Delhi - 110029 , India.

E-mail: c.arvind61@yahoo.in 
affect CBF, although it decreased the cerebral metabolic rate for oxygen $\left(\mathrm{CMRO}_{2}\right)$. However the effects of $\mathrm{N}_{2} \mathrm{O}$ on CBFV are preserved in children during propofol anesthesia. ${ }^{[1]}$ It is now generally agreed that $\mathrm{N}_{2} \mathrm{O}$ increases $\mathrm{CBF}, \mathrm{CMRO}_{2}$ and ICP. The most dramatic increase in CBF and ICP occurred when $\mathrm{N}_{2} \mathrm{O}$ was administered alone or with other minimal background anesthetics. The increase in $\mathrm{CBF}$ and $\mathrm{CMRO}_{2}$ with $\mathrm{N}_{2} \mathrm{O}$ do not appear to be related solely to sympathetic hyperactivity. $\mathrm{N}_{2} \mathrm{O}$ appears to be related to have no direct vasodilating effect. ${ }^{[2]}$ Potential benefits of induced hypocapnia in patients with intracranial pathology may be offset by the use of $\mathrm{N}_{2} \mathrm{O} \cdot{ }^{[3]}$

\section{Halothane}

In most animal experiments, it was found that halothane produces an increase in $\mathrm{CBF}$ with a decrease in cerebrovascular resistance (CVR). In humans also, most studies demonstrated that halothane induces cerebral vasodilation and increases $C B F$. The increase in cortical $\mathrm{CBF}$ appears greater with halothane than with enflurane or isoflurane at equal minimal alveolar concentration (MAC). The mechanism of the cerebral vasodilation produced by halothane has not been thoroughly understood. A direct effect on vascular smooth muscles or an increase in cyclic adenosine monophosphate (cAMP) in the brain has been postulated, but the evidence is inconclusive. Nitric oxide (NO) might be an important mediator of cerebral vasodilation produced by volatile agents. ${ }^{[4-6]}$ In both animals and humans, halothane raises ICP in a dose related fashion. The rise in ICP with halothane is maximum among the commonly used volatile anesthetics. However, at 0.5 MAC or less, the effect on ICP is minimal.

\section{Isoflurane}

Most animal studies show that isoflurane produces an increase in $\mathrm{CBF}$ accompanied by a decrease in CVR and $\mathrm{CMRO}_{2}$ except at low concentration. It has been found that isoflurane is safe to use in patients with small supratentorial tumors in whom only a small midline shift has occurred. ${ }^{[7]}$ In a PET study in humans, isoflurane $(0.2$ to $1.0 \%$ ) was reported to produce no change in global $\mathrm{CBF}^{[8]}$ The increase in ICP caused by isoflurane, is mild and can be prevented by induced hypocapnia.

\section{Enflurane}

The effect of enflurane, a stereoisomer of isoflurane, are intermediate between those of isoflurane and halothane. Because of enflurane's potential effects on ICP and possible epileptogenic properties, high concentrations of the agent should be avoided in patients at risk. Low dose of enflurane can be used safely, but this agent does not seem to be useful in neurosurgical anesthesia.

\section{Sevoflurane}

PET demonstrated that either a decrease ${ }^{[9]}$ or no change ${ }^{[10]}$ in global CBF occurred with use of sevoflurane. It can be the result of reduction in CBF caused by CMR suppression. ${ }^{[11]}$ Middle cerebral artery velocity (Vmca) has been reported to be either decreased, ${ }^{[12]}$ unchanged $^{[13]}$ or increased with sevoflurane (at less magnitude than with isoflurane). ${ }^{[14]}$ Sevoflurane produces small increase in ICP in both animals and humans and this can be blocked by hyperventilation. The extent of the increase in ICP is in the order: Desflurane $>$ isoflurane $>$ sevoflurane. ${ }^{[15]}$

\section{Desflurane}

Desflurane has been reported to produce a dose dependent increase in $\mathrm{CBF}$ and a decrease in $\mathrm{CMRO}_{2}{ }^{[16]}$ Because of its low blood/gas partition coefficient $(0.42)$ relative to other clinically used volatile inhalational anesthetics, desflurane can provide rapid onset and offset of anesthesia, which facilitates early neurological evaluation. Desflurane at $1 \mathrm{MAC}$ decreases $\mathrm{CMRO}_{2}$ by $50 \%$ and $\mathrm{CBF}$ by $22 \%$ and preserves cerebrovascular $\mathrm{Co} 2$ reactivity. ${ }^{[17]}$

\section{Intravenous Anesthetic Drugs}

Barbiturates

Barbiturates were the first anesthetics to be examined for their cerebral vascular effects. Thiopental decreases $\mathrm{CBF}$ and cerebral metabolic rate for oxygen consumption $\left(\mathrm{CMRO}_{2}\right)$ in a parallel fashion up to the point of isoelectricity on the electroencephalogram (EEG). The changes in $\mathrm{CBF}$ are thought to be secondary to the changes in $\mathrm{CMRO}_{2}$ (a coupled decrease in flow and metabolism). At the point of isoelectric EEG after the administration of thiopental, an approximately 50\% decrease in $\mathrm{CMRO}_{2}$ occurs without any toxicity. If high dose of barbiturates is used for cerebral protection, the endpoint of EEG burst suppression is often used to provide near-maximal metabolic suppression. However, the associated hypotension may require concomitant use of a vasopressor to maintain cerebral perfusion pressure (CPP).

Thiopental, even in high doses, does not appear to abolish cerebral autoregulation or $\mathrm{CO}_{2}$ reactivity. As a result of the reduction in both $\mathrm{CBF}$ and cerebral blood volume (CBV), barbiturates lower ICP. Barbiturates are used clinically for this purpose and may even be effective when other methods for reducing ICP have failed.

\section{Etomidate}

Etomidate, like the barbiturates, reduces CBF and $\mathrm{CMRO}_{2}$. An isoelectric EEG can be induced with etomidate, and, as with thiopental, there is no evidence of cerebral toxicity as reflected by normal brain metabolites. In addition, no further reduction in $\mathrm{CMRO}_{2}$ occurs when 
additional doses are given after EEG burst suppression is achieved. A maximal decrease in CBF was achieved before the maximal decrease in $\mathrm{CMRO}_{2} \cdot{ }^{[18]}$ Myoclonus produced by the drug has the disadvantage of being misinterpreted as seizure activity in neurosurgical patients. Prolonged use of etomidate may suppress the adrenocortical response to stress. Less cardiovascular depression with etomidate as compared to thiopental makes this drug advantageous for the induction of anesthesia in trauma and elderly patients. Etomidate has also been shown to reduce ICP without decreasing CPP.

\section{Propofol}

Propofol produces dose-related reductions in both CBF and $\mathrm{CMRO}_{2}$. In neurosurgical patients who are hypovolemic, the reduction in MAP might be substantial when they receive large bolus doses of propofol. A continuous infusion of propofol may be used intraoperatively as part of a total intravenous anesthesia (TIVA). The combination of an infusion of propofol and a narcotic (such as remifentanil) is particularly useful when the monitoring of evoked potentials precludes the use of other than low concentrations of inhalational drugs. Propofol is also useful for sedation during awake craniotomies and as a substitute for an inhalational drug at the end of a general anesthetic to shorten the wake-up time.

Autoregulation and $\mathrm{CO}_{2}$ response are preserved during the administration of propofol. Because it also reduces MAP, its effect on CPP must be carefully monitored. Nonetheless, propofol's ICP-lowering effect makes it useful in the intensive care unit (ICU) for the sedation of patients in whom elevated ICP is a concern. Propofol has the advantage of allowing prompt awakening which is advantageous in patients whose neurologic status needs to be evaluated serially. In the operating room, moderately deep sedation with propofol does not increase ICP in comparison to no sedation in patients undergoing stereotactic biopsy for brain tumors. During craniotomy for resection of brain tumors, ICP has been shown to be lower in patients who receive propofolfentanyl in comparison to patients anesthetized with isoflurane-fentanyl or sevoflurane-fentanyl. The vasoconstrictive activity of propofol may be suitable for carotid endartectomy ${ }^{[19]}$ and revascularization surgery for moyamoya disease, ${ }^{[20]}$ because the cerebral steal phenomenon can be avoided with propofol.

The antiemetic effect of propofol is also advantageous in neurosurgical patients because many of them receive large doses of narcotics, which are associated with a high incidence of nausea and vomiting leading to rise in ICP. Careful attention to sterile technique is essential when using propofol as an infusion because the solubilizing agent in which propofol is prepared provides an excellent medium for bacterial growth.

\section{Narcotics (opioids)}

The effects of narcotics on CBF are difficult to characterize due to conflicting experimental reports. It appears, however, that low doses of narcotics have little effect on $\mathrm{CBF}$ and $\mathrm{CMRO}_{2}$ whereas higher doses progressively decrease both $\mathrm{CBF}$ and $\mathrm{CMRO}_{2}$. The reductions in $\mathrm{CBF}$ and $\mathrm{CMRO}_{2}$ parallel progressive slowing of the EEG. However, burst suppression and an isoelectric EEG are never achieved. High doses of narcotics have been shown to produce seizures in laboratory animals but rarely in humans. Cerebral autoregulation and $\mathrm{CO}_{2}$ reactivity are maintained with narcotics.

Under most conditions, narcotics produce either no change or a slight decrease in ICP. Narcotics can, however, increase ICP under certain study conditions. For example, the bolus administration of sufentanil has been shown to produce transient increase in ICP in patients who have severe head injury. ${ }^{[21,22]}$ Thus, when narcotics are administered to the neurosurgical patient, they should be given in a manner that does not cause a sudden reduction in MAP. The narcotic antagonist naloxone, when carefully titrated, has little effect on CBF and ICP. When used in large doses to reverse narcotic effects, use of naloxone may be associated with hypertension, cardiac arrhythmias, and intracranial hemorrhage.

\section{Ketamine}

Ketamine produces an increase in $\mathrm{CBF}$ and $\mathrm{CMRO}_{2}$. The mechanism of the increase may be manifold in CBF. Respiratory depression with mild hypercapnia in spontaneously ventilating subjects, regional neuroexcitation with a concomitant increase in cerebral metabolism and direct cerebral vasodilatation. Although seizures have been reported in epilepsy patients receiving ketamine, generally no epileptiform activity is seen on EEG analysis. Cerebral autoregulation and $\mathrm{CO}_{2}$ reactivity are maintained with ketamine.

During spontaneous ventilation, ketamine produces an increase in $\mathrm{PaCO}_{2}$ and ICP, in both the presence and absence of pre-existing intracranial hypertension. Thus, it is usually avoided in most neurosurgical patients. Interestingly, ketamine is a noncompetitive $\mathrm{N}$-methyldaspartate antagonist. In an animal model of incomplete cerebral ischemia, so ketamine was shown to reduce cerebral infarct size.

Benzodiazepines

Benzodiazepines, including diazepam, midazolam and lorazepam, produce small decrease in $\mathrm{CBF}$ and $\mathrm{CMRO}_{2}$ 
with both small and large doses. Contrary to the assumption that ICP would be reduced because of a lower CBF, diazepam $(0.25 \mathrm{mg} / \mathrm{kg})$ did not change ICP. ${ }^{[23]}$ As with the barbiturates, some of the CBF-lowering effect of benzodiazepines is thought to be secondary to a reduction in $\mathrm{CMRO}_{2}$. Benzodiazepines are known anticonvulsants and are used clinically for this purpose.

$\mathrm{CBF}$ autoregulation and $\mathrm{CO}_{2}$ reactivity are maintained with benzodiazepines. ICP effects are small with benzodiazepines, which cause either no change or a slight reduction in ICP. Midazolam is commonly used as a premedication in neuroanesthesia, with small intravenous doses titrated to the patient's response and as an anesthetic adjuvant.

\section{Muscle Relaxants}

Muscle relaxants do not cross the blood-brain barrier. Any cerebral effects are thus secondary to histamine release, systemic hemodynamic changes, actions of metabolites and altered cerebral afferent input.

\section{Nondepolarizing Muscle Relaxants}

Short-acting drug like Mivacurium metabolized by plasma cholinesterase and undergoes ester hydrolysis in the liver. It is commonly given by infusion because of its rapid metabolism. When large doses of mivacurium are given rapidly, histamine release can occur which can cause rise in $\mathrm{CBF}$ and ICP.

Intermediate-acting drugs like Atracurium can also release histamine when given in large bolus doses. It is metabolized by ester hydrolysis and Hoffmann elimination, so in patients with renal or liver dysfunction, its metabolism is not affected. Laudanosine, a metabolite of the Hoffmann elimination of atracurium, has been shown to cause seizures in laboratory animals. The newer analog of atracurium, cis-atracurium, does not cause histamine release and formation of toxic metabolites.

Vecuronium has the advantage of maintaining stable hemodynamics even when given in large doses. One possible exception is that bradycardia may occur when vecuronium is combined with large doses of narcotics for induction of anesthesia, leaving the vagotonic effect of the narcotic unopposed. Its stable hemodynamics and lack of cerebral effects have made vecuronium a popular choice in neuroanesthesia.

Rocuronium has a relatively stable hemodynamic profile (weakly vagolytic) and is excreted unchanged by the biliary system and the kidneys. Unlike vecuronium, it is not associated with the production of active metabolites. The rapid onset of rocuronium makes it an excellent choice for intubation in the neurosurgical patient who is at risk for succinylcholine side effects.

Long-acting drug like Pancuronium causes hypertention and tachycardia leading to rise in CBF and ICP and which is rarely used now-a-days.

Depolarizing muscle relaxants Succinylcholine can cause an increase in CBF and ICP. This is secondary to muscle fasciculation, which increase cerebral afferent input. ${ }^{[24]}$ The changes in ICP are modest and transient. The other greater concern is the large release of potassium that occurs with certain neurologic injuries such as closed head trauma, cerebrovascular accidents, hemiparesis, spinal cord trauma, and neuromuscular disorders.

\section{Positioning}

Patient positioning for optimal surgical access during neurosurgery may have major implications for the neuroanesthetist and neurosurgeon.

\section{Supine position}

Patients with cerebellopontine angle tumors (e.g. acoustic neuromas) are often operated on in this position. However, access to the posterior fossa often requires substantial lateral rotation of the head, resulting in stretching of the jugular veins and brachial plexus. In patients undergoing craniotomy for cerebral aneurysm, a 10 degree reverse Trendelenburg tilt decrease ICP, although the CPP remain unchanged. ${ }^{[25]}$

Prone position

The prone position offers good access to midline structures but bleeding can obscure the surgical field. Head-up tilt is used to reduce hemorrhage but this increases the risk of air embolism. The chest and iliac crests should be well supported to ensure free movement of the abdomen during respiration. Obese patients are at particular risk because of restricted diaphragmatic movement. The head is fixed in clamps in preference to a horseshoe to minimize pressure on the face and eyes. Pressure points should be well padded and the tracheal tube kept as secure as possible. In children with brain tumors, brain swelling and ICP rise is higher in the prone position than in supine. ${ }^{[26]}$

\section{Lateral position}

The lateral position is suitable for approaches to lesions not in the midline, particularly the cerebellopontine angle. This position facilitates gravitational retraction of the dependent cerebellum and facilitates CSF and venous drainage. A variation called the 'park bench' position is often used because of its resemblance to the way a tramp sleeps on a park bench. A pad should be placed under the body in the axilla to minimize weight 
on the lower arm and shoulder. The head is fixed in pins. Excessive flexion of the neck can obstruct the internal jugular veins. This can be avoided by ensuring a two or three fingers-breadth gap between chin and sternal notch.

\section{Sitting position}

The sitting position though rarely used, provides good surgical access to midline structures, improves surgical orientation and allows good drainage of blood and CSF. Functional residual capacity and vital capacity are improved and access to the airway is facilitated.

However, there are increased risks of cord compression, pneumocephalus and venous air embolism. Macroglossia and peripheral nerve injuries are also more common in the sitting position. Hypotensive techniques increase the risks of ischemic damage. Many authorities now contend that with modern anesthetic techniques there is no place for the sitting position in neuroanesthesia. Excessive head-up tilt in other positions, however, exposes the patient to similar risks. Despite the well-recognized complications of the sitting position, several case series have established its relative safety in carefully selected patients. ${ }^{[27,28]}$ A magnetic resonance imaging (MRI) study in healthy volunteers supports the clinical findings of an improvement in cerebrovascular and intracranial compliance in sitting position. ${ }^{[29]}$

Although one of the oldest subspecialties of surgery, modern neurosurgery is where some of the greatest changes are happening and neuroanesthesia practice must keep pace. Although the basic principles remain the same, new challenges are faced as indications for functional and minimally invasive neurosurgery are increasing. Anesthesia provision for these new procedures may be very different, require new management strategies, and pose new risks. We may never reach a consensus on the ideal drug or the perfect recipe for neuroanesthesia and continue to choose drugs and techniques which accommodate specific surgical requirements and personal preferences. However, as technological advances and new anesthetic techniques push the boundaries of what or who is treatable more than ever; close cooperation among the neurosurgeon, neuroanesthetist, and patient is vital.

\section{REFERENCES}

1. Wilson-Smith E, Karsli C, Luginbuehl IA, Bissonnette B. The effect of nitrous oxide on cerebral blood flow velocity in children anesthetized with propofol. Acta Anaesthesiol Scand 2003;47:307-11.

2. Reinstrup P, Ryding E, Algotsson L, Berntman L, Uski T. Effects of nitrous oxide on human regional cerebral blood flow and isolated pial arteries. Anesthesiology 1994;81:396-402.
3. Watts AD, Luney SR, Lee D, Gelb AW. Effect of nitrous oxide on cerebral blood flow velocity after induction of hypocapnia. J Neurosurg Anesthesiol 1998;10:142-5.

4. Koenig HM, Pelligrino DA, Albrecht RF. Halothane vasodilation and nitric oxide in rat pial vessels. J Neurosurg Anesthesiol 1993;5:264-71.

5. McPherson RW, Kirsch JR, Moore LE, Traystman RJ. N omega-nitro-Iarginine-nitro- arginine methyl ester prevents cerebral hyperemia by inhaled anesthetics in dogs. Anesth Analg 1993;77:891-7.

6. Moore LE, Kirsch JR, Helfaer MA, Tobin JR, McPherson RW, Traystman RJ. Nitric oxide and prostanoids contribute to isofluraneinduced cerebral hyperemia in pigs. Anesthesiology 1994;80:1328-37.

7. Madsen JB, Cold GE, Hansen ES, Bardrum B. The effect of isoflurane on cerebral blood flow and metabolism in humans during craniotomy for small supratentorial cerebral tumors. Anesthesiology 1987;66:332-6.

8. Schlünzen L, Cold GE, Rasmussen M, Vafaee MS. Effects of dosedependent levels of isoflurane on cerebral blood flow in healthy subjects studied using positron emission tomography. Acta Anaesthesiol Scand 2006;50:306-12.

9. Kaisti KK, Metsähonkala L, Teräs M, Oikonen V, Aalto S, Jääskeläinen S, et al. Effects of surgical levels of propofol and sevoflurane anesthesia on cerebral blood flow in healthy subjects studied with positron emission tomography. Anesthesiology 2002;96:1358-70.

10. Schlünzen L, Vafaee MS, Cold GE, Rasmussen M, Nielsen JF, Gjedde A. Effects of subanaesthetic and anaesthetic doses of sevoflurane on regional cerebral blood flow in healthy volunteers: A positron emission tomographic study. Acta Anaesthesiol Scand 2004;48:1268-76.

11. Reinstrup P, Ryding E, Algotsson L, Berntman L, Uski T. Effects of nitrous oxide on human regional cerebral blood flow and isolated pial arteries. Anesthesiology 1994;81:396-402.

12. Cho S, Fujigaki T, Uchiyama Y, Fukusaki M, Shibata O, Sumikawa K. Effects of sevoflurane with and without nitrous oxide on human cerebral circulation: Transcranial Doppler study. Anesthesiology 1996;85:755-60.

13. Kuroda Y, Murakami M, Tsuruta J, Murakawa T, Sakabe T. Blood flow velocity of middle cerebral artery during prolonged anesthesia with halothane, isoflurane, and sevoflurane in humans. Anesthesiology 1997;87:527-32.

14. Matta BF, Heath KJ, Tipping K, Summors AC. Direct cerebral vasodilatory effects of sevoflurane and isoflurane. Anesthesiology 1999;91:677-80.

15. Hölmstrom A, Åkeson J. Desflurane increases intracranial pressure more and sevoflurane less than isoflurane in pigs subjected to intracranial hypertension. J Neurosurg Anesthesiol 2004;16:136-43.

16. Lutz LJ, Milde JH, Milde LN. The cerebral functional, metabolic, and hemodynamic effects of desflurane in dogs. Anesthesiology 1990;73:125-31.

17. Mielck F, Stephan H, Buhre W, Weyland A, Sonntag H. Effects of 1 MAC desflurane on cerebral metabolism, blood flow and carbon dioxide reactivity in humans. Br J Anaesth 1998;81:155-60.

18. Milde LN, Milde JH, Michenfelder JD. Cerebral functional, metabolic, and hemodynamic effects of etomidate in dogs. Anesthesiology 1985;63:371-7.

19. McCulloch TJ, Thompson CL, Turner MJ. A randomized crossover comparison of the effects of propofol and sevoflurane on cerebral hemodynamics during carotid endarterectomy. Anesthesiology 2007;106:56-64.

20. Kikuta K, Takagi Y, Nozaki K, Yamada K, Miyamoto S, Kataoka H, et al. Effects of intravenous anesthesia with propofol on regional cortical blood flow and in tracranial pressure in surgery for moyamoya disease. Surg Neurol 2007;68:421-4.

21. Albanese J, Durbec O, Viviand X, Potie F, Alliez B, Martin C. Sufentanil increases intracranial pressure in patients with head trauma. Anesthesiology 1993;79:493-7.

22. Sperry RJ, Bailey PL, Reichman MV, Peterson JC, Petersen PB, Pace NL. Fentanyl and sufentanil increase intracranial pressure in head trauma patients. Anesthesiology 1992;77:416-20.

23. Tateishi A, Maekawa T, Takeshita H, Wakuta K. Diazepam and intracranial pressure. Anesthesiology 1981;54:335-7.

24. Lanier WL, laizzo PA, Milde JH. Cerebral blood flow and afferent muscle activity following IV succinylcholine in dogs. Anesthesiol Rev 1987; 14:60-66.

25. Tankisi A, Rasmussen M, Juul N, Cold GE. The effects of 10 degrees reverse Trendelenburg on subdural intracranial pressure and cerebral 
perfusion pressure in patients subjected to craniotomy for cerebral aneurysm. J Neurosurg Anesthesiol 2006;18:11-7.

26. Stilling M, Karatasi E, Rasmussen M, Tankisi A, Juul N, Cold GE. Subdural intracranial pressure, cerebral perfusion pressure and degree of cerebral swelling in supra- and infra-tentorial space occupying lesions in children. Acta Neurochir Suppl 2005;95:133-6.

27. Harrison EA, Mackersie A, McEwan A, Facer E. The sitting position for neurosurgery in children: A review of 16 years experience. $\mathrm{Br} \mathrm{J}$ Anaesth 2002;88:12-7.

28. Leslie K, Hui R, Kaye AH. Venous air embolism and the sitting position: A case series. J Clin Neurosci 2006;13:419-22.
29. Alperin N, Hushek SG, Lee SH, Sivaramakrishnan A, Lichtor T. MRI study of cerebral blood flow and CSF flow dynamics in an upright posture: The effect of posture on the intracranial compliance and pressure. Acta Neurochir Suppl 2005;95:177-81.

How to cite this article: I, Chaturvedi A. What our colleagues says.... Basic anesthetic considerations in neurosurgery. Indian J Neurosurg 2012;1:66-71.

Source of Support: Nil, Conflict of Interest: None declared.

Announcement

INTERNATIONAL CONFERENCES, 2012

No. Conference Date Location Contact information

1. $8^{\text {th }}$ International Congress on Meningiomas and May 1-6, 2012 Cerebral Venous System

2. World Federation of Skull Base Societies $6^{\text {th }}$ International Congress

3. $32^{\text {nd }}$ Meeting of the Japanese Congress of Neurological Surgeons (JCNS)

4. The Society of Neurological Surgeons Annual May 19-22, 2012 Meeting

5. $9^{\text {th }}$ Annual World Congress for Brain, Spinal Cord June 2-4, 2012 Mapping \& Image Guided Therapy

6. Neurosurgical Society of America Annual June 10-13, 2012 Meeting (NSA 2012)

7. Biennial Meeting - American Society for Stereotactic and Functional Neurosurgery

8. $11^{\text {th }}$ Biennial Congress of the International Stereotactic Radiosurgery Society

9. $\quad 3^{\text {rd }}$ World Congress of Minimally Invasive Spine Surgery and Techniques

10. $5^{\text {th }}$ International Cerebrovascular and Skull Base September 6-8, 2012 Workshop

11. $9^{\text {th }}$ Asian Congress of Neurological Surgeons (ACNS 2012)

12. The XX Congress of the European Society for Stereotactic and Functional Neurosurgery

13. International Spinal Cord Society (ISCOS 2012)

14. $62^{\text {nd }}$ Annual Meeting of the Congress of Neurological Surgeons

15. American Academy of Neurological Surgery $74^{\text {th }}$ October $17-20,2012$ Annual Meeting

16. EANS Annual Meeting 2012

17. 2012 Japan India Neurosurgical Conference

18. Cervical Spine Research Society Meeting
May 16-19, 2012

Mumbai, India

Brighton, UK

Yokohama, Japan

Atlanta, USA

Toronto, Canada

Park City, Utah, USA

June 3-6, 2012

June 16-20, 2012

August 16-18, 2012

September 2-5, 2012

September 26-29, 2012

September 3-5, 2012

October 6-11, 2012

October 24-27, 2012

October 19-20, 2012

December 6-8, 2012
San Franscisco, California, USA

Toronto, Canada

Bahia, Brazil

Kyiv, Ukraine

Istanbul, Turkey

Lisbon, Portugal

Chicago, Illinois, USA

Cape Cod, USA

Bratislava, Slovakia

Osaka, Japan

Chicago, USA http://www.neurosurgery2012.org/

http://www2.kenes.com/skullbase/Pages/ Home.aspx

http://wwwsoc.nii.ac.jp/jcns/english/ meetings.html

http://www.societyns.org/meeting_info. html

http://www.worldbrainmapping.org/

http://www.neurosurgicalsociety.com/cal/ event_list.asp?ID=151

http://www.assfn.org/\#

http://www.isrsy.org/view.php?id_27

http://www.wcmisst2012.com.br/

http://www.skullbase2012.org.ua

http://www.acns2012.com/

http://www.essfn2012.org/

http://www2.kenes.com/iscos2012/Pages/ Home.aspx

http://w3.cns.org/meetings/2012/index.asp

http://americanacademyns.org/content. aspx?id=34

http://www.eans.org/events/event-59/

kohata@med.osaka-cu.ac.jp http://www.csrs.org/web/index.html

\section{NATIONAL CONFERENCES, 2012}

\begin{tabular}{|c|c|c|c|c|}
\hline No. & Conference & Date & Location & Contact information \\
\hline 1. & $\begin{array}{l}21^{\text {st }} \text { Annual Conference of the National Neurotrauma Society Of } \\
\text { India, Neurotrauma } 2012\end{array}$ & August 17-19, 2012 & Kochi, Kerala & www.neurotrauma2012.com \\
\hline 2. & $\begin{array}{l}14^{\text {th }} \text { Annual Conference of the Skull Base Society of India } \\
\text { SKULLBASE } 2012\end{array}$ & September 23-24, 2012 & Mumbai & skullbase2012@gmail.com \\
\hline 3. & $\begin{array}{l}\text { Annual Conference of Indian Society of Pediatric Neurosurgery, } \\
\text { NEUROPEDICON } 2012\end{array}$ & November 1-2, 2012 & New Delhi & www.neuropedicon2012.com \\
\hline 4. & $61^{\text {st }}$ Annual Conference of Neurological Society of India & December 19-22, 2012 & New Delhi & www.neurocon2012.com \\
\hline
\end{tabular}

